\title{
SITE SELECTION AND EVALUATION OF CHINA'S NEW RADIOMETRIC CALIBRATION TEST SITES
}

\author{
Hu Xinkai ${ }^{1}$, Gao Hailiang ${ }^{2 *}$, Cheng Tianhai ${ }^{2}$, Tang Shihua ${ }^{1}$, Liu Li $^{3}$, Liu Qiyue $^{2}$ \\ ${ }^{1}$ Surveying and Mapping Geography, Guilin University of Technology, Guilin, Guangxi 541006, China; \\ ${ }^{2}$ National Engineering Laboratory for Remote Sensing Satellite Applications, Institute of Remote Sensing and Digital \\ Earth, Chinese Academy of Sciences, Beijing 100012, China; \\ ${ }^{3}$ Calibration and Validation Department, China Centre for Resources Satellite Data and Application, Beijing 100094, \\ China
}

KEY WORDS: Radiometric Calibration, Site Selection, Surface Characteristics, Atmospheric Characteristics, Site Evaluation

\begin{abstract}
:
The ideal radiometric calibration site is the basis for achieving on-orbit radiometric calibration. At present, China mainly uses the Dunhuang national test site for on-orbit radiometric calibration. However, the Dunhuang national test site has a shortage of ground objects and surface damage, and it is urgent to select and evaluate the new calibration sites. By analyzing the calibration site selection requirements, three new radiometric calibration sites were selected in Dunhuang and Golmud. Obtaining high-resolution satellite image data of each calibration site and evaluating the spatial uniformity of the site on different spatial scales. The radiometric stability of the sites is evaluated using the long-term sequence of Landsat8 image data from 2013 to 2019. Atmospheric and surface tests were carried out at various sites in August 2019, and atmospheric information and ground spectral data were obtained to evaluate the spectral characteristics of the sites. The surface directional characteristics of the sites are evaluated by using MODIS images at different angles in sunny weather on adjacent dates. Obtaining MOD05 water vapor products from 2013 to 2019 of each calibration site and conducting monthly statistics. The number of sunny days at each calibration site is counted and the drought conditions of the site are evaluated. The results show that the three new radiometric calibration sites have uniform and stable surface characteristics and atmospheric characteristics, and are suitable for on-orbit radiometric calibration of satellite sensors, which provides a reference for the location and evaluation of future calibration sites.
\end{abstract}

\section{Introduction}

With the in-depth application of different series of satellites such as meteorological satellites, resource satellites, marine satellites, environmental satellites and mapping satellites in various industries, the demand for quantitative remote sensing is becoming more and more urgent. Radiometric calibration is the premise of quantitative remote sensing, and its accuracy directly affects the reliability and accuracy of quantitative application of remote sensing data ${ }^{[1]}$. Radiometric calibration not only characterizes the state of satellite sensors after launch and degradation over time, but also establishes the physical relationship between multi-source remote sensing data and expands the quantitative remote sensing data source ${ }^{[2]}$. Therefore, high-precision radiometric calibration plays an important role in the development of quantitative remote sensing, and the ideal

*E-mail:gaohl@radi.ac.cn

Fund project: National Key R\&D Program of China, 2018YFB0504900, 2018YFB0504903 radiometric calibration site is the basis for achieving on-orbit radiometric calibration.

At present, China mainly uses the Dunhuang national test site for on-orbit radiometric calibration of satellite sensors. The Dunhuang national test site has the advantages of flat ground, single type of land, large area, and clean atmosphere. Since the 1990s, many sensors have been successfully calibrated on-orbit and recognized internationally. It is one of the recommended on-orbit calibration sites ${ }^{[3]}$. However, the type of the Dunhuang national test site is too single to be able to carry out multi-point calibration and authenticity test, and the test site is affected by natural weather such as sandstorms and cloud rain, and the number of calibrations is limited ${ }^{[4]}$. In addition, with the development of ground synchronization tests in the Dunhuang national test site for many years, the surface damage has become increasingly serious, and the surrounding human activities have gradually increased. It 
is urgent to establish new calibration sites to meet the increasing demand for on-orbit calibration and authenticity test in China. Therefore, the site selection work was carried out in Dunhuang and Golmud. In the Dunhuang area, the Dunhuang new test site was selected, and in the Golmud area, the Dazaohuo east and the Dazaohuo west were selected. In August 2019, atmospheric and surface tests were carried out on each site, and the characteristics of the sites were evaluated using ground-measured data and historical satellite images.

The first section of this paper gives an overview of the current status and existing problems of the calibration sites; The second section introduces the site selection principles and site characteristics evaluation indexes; the third section introduces the radiometric calibration sites; the fourth section carries out the analysis of the evaluation indexes; the final section gives the relevant conclusions.

2. Calibration site selection principles and site characteristics evaluation indexes

The selection of the radiometric calibration site is the key link in the on-orbit calibration, which directly affects its accuracy. In order to reduce the uncertainty of each link in the on-orbit calibration process, it is necessary to consider the surface characteristics and atmospheric characteristics of the site ${ }^{[5]}$. Site surface characteristics include spatial uniformity, radiometric stability, spectral characteristics and surface directional characteristics; site atmospheric characteristics include site water vapor content, the number of sunny days, and so on. The site selection principle of the radiometric calibration site and the site characteristics evaluation indicators are as follows:

\section{(1) Spatial uniformity}

The test site with good spatial uniformity can not only meet the needs of different spatial resolution satellite calibration, but also reduce the influence of poor registration; it can also reduce the mixed pixel error caused by ground measurement instruments. The spatial uniformity of the site selects the high-resolution satellite full-color image of the test area, and the uniformity is evaluated by the coefficient of variation of the site gray value.

(2) Radiometric stability

The surface of the test site should be as uniform as possible, usually requiring no vegetation cover, such as desert and Gobi. Using the time series Landsat8 satellite imagery, the apparent reflectance of different phases is calculated to achieve radiometric stability evaluation.

\section{(3) Spectral characteristics}

The reflectance spectral curve of the calibration test site is smooth with no obvious peaks and troughs. This can reduce the spectral response matching error of the sensor and facilitate the cross calibration of the satellite sensor. The measured spectra of different test sites in the same time period were compared to evaluate the spectral characteristics.

(4) Surface directional characteristics

The directional characteristics of the site are evaluated using the site's BRDF measurement data or satellite multi-angle images. The surface directional characteristics of the site are obtained by calculating the relative difference in apparent reflectance of MODIS images on adjacent dates.

(5) Water vapor content and the number of sunny days

The calibration test site should select arid areas, which can not only reduce the change of surface reflectance caused by rainfall, but also have more sunny days to test. Using the time series water vapor content of MODIS, the monthly average water vapor content is obtained; the historical weather query is used to count the number of sunny days at each site.

\section{Calibration sites introduction}

\section{(1) Dunhuang national test site}

Since the end of the 1990s, the Dunhuang national test site has been used for calibration tests of Chinese satellites. It is located $15 \mathrm{~km}$ west of Dunhuang City, and the site is large, flat and homogeneous. The coordinates are $40.093^{\circ} \mathrm{N}$ and $94.394^{\circ} \mathrm{E}$, and the altitude is $1253 \mathrm{~m}$. There are very few disturbances and low aerosol loads from the clouds, no vegetation on the ground, composed of sand and small black stones ${ }^{[6]}$. In addition, the surface reflectance spectrum is relatively stable within the dynamic range of the optical satellite sensor. Therefore, the Dunhuang national test site has been widely used for the calibration of GF-1/PMS, WFV, CBERS-02/CCD, FY-3A/MERIS, HJ-1A, 1B/CCD and other sensors ${ }^{[7]}$.

(2) Dunhuang new test site

As there are solar power stations near the Dunhuang national test site, this will have an impact on the calibration tests. In this paper, Landsat8 image data is used to determine a most uniform area of $5 \mathrm{~km} \times 5 \mathrm{~km}$ in 
Dunhuang, namely the Dunhuang new test site. It is located $6 \mathrm{~km}$ west of the Dunhuang national test site, its coordinates are $40.087^{\circ} \mathrm{N}$ and $94.326^{\circ} \mathrm{E}$, and the altitude is $1261 \mathrm{~m}$. The other conditions of the site are basically the same as those of the Dunhuang national test site. In late August 2019, the China Centre for Resources Satellite Data and Application conducted site spectral measurement at the Dunhuang new test site, and obtained the measured surface reflectance

(3) Dazaohuo east

Using the Landsat8 image data, the most uniform area of $5 \mathrm{~km} \times 5 \mathrm{~km}$ was identified in Golmud, namely the Dazaohuo east. The Dazaohuo east is located 60 kilometers west of Golmud City, Qinghai Province. Its coordinates are $36.389^{\circ} \mathrm{N}$ and $94.209^{\circ} \mathrm{E}$, with an elevation of $2881 \mathrm{~m}$. In early August 2019, the Institute of Remote Sensing and Digital Earth of the Chinese Academy of
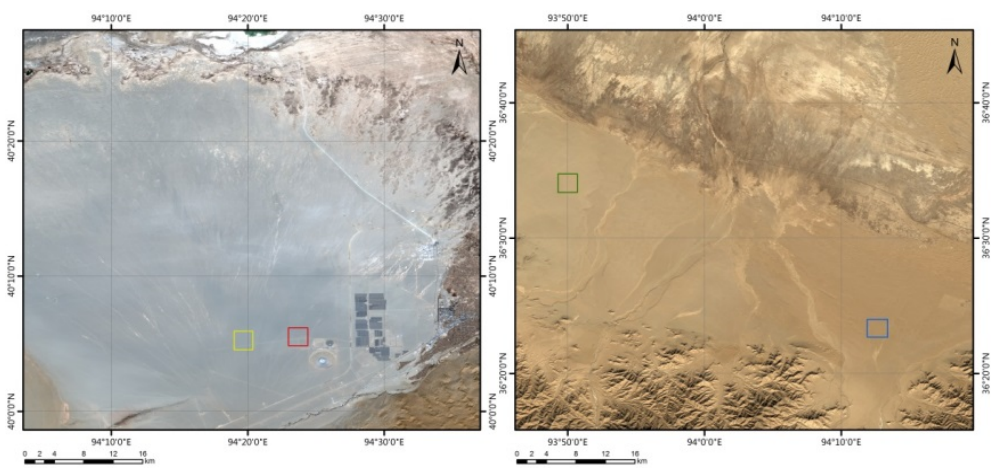

Figure 1. Location of each calibration site

red: Dunhuang national test site; yellow: Dunhuang new test site; blue: Dazaohuo east; green: Dazaohuo west

\section{Analysis of the site evaluation indexes}

\subsection{Site Spatial uniformity}

Quantitative evaluation of site spatial uniformity is performed using high-resolution satellite full-color image data. Obtaining a cloudless image data of each site, with
Sciences conducted site spectral measurement at the Dazaohuo east, and obtained the measured surface reflectance.

(4) Dazaohuo west

Using the Landsat 8 image data, another $5 \mathrm{~km} \times 5 \mathrm{~km}$ most uniform area was identified in Golmud, namely the Dazaohuo west. The Dazaohuo west is located 95 kilometers west of Golmud City, Qinghai Province. Its coordinates are $36.568^{\circ} \mathrm{N}$ and $93.834^{\circ} \mathrm{E}$, with an elevation of $2856 \mathrm{~m}$. In early August 2019, the Institute of Remote Sensing and Digital Earth of the Chinese Academy of Sciences conducted site spectral measurement at the Dazaohuo west, and obtained the measured surface reflectance. The figure 1 shows two WFV images over Dunhuang and Golmud. The boxes in these two figures are the core test areas. the site latitude and longitude as the center point, dividing the site into $100 \mathrm{~m} \times 100 \mathrm{~m}, 500 \mathrm{~m} \times 500 \mathrm{~m}, 1 \mathrm{~km} \times 1 \mathrm{~km}$ and $5 \mathrm{~km} \times 5 \mathrm{~km}$, and calculating the coefficient of variation of the gray value, as shown in Table 1.

Table 1 Site space uniformity

\begin{tabular}{|c|c|c|c|c|c|c|}
\hline \multirow{2}{*}{ Site } & \multicolumn{3}{|c|}{ Coefficient of variation\% } & \multirow{2}{*}{ Satellite sensor } & \multirow{2}{*}{ Image time } \\
\cline { 2 - 6 } & $100 \mathrm{~m}$ & $500 \mathrm{~m}$ & $1000 \mathrm{~m}$ & $5000 \mathrm{~m}$ & & \\
\hline Dunhuang national test site & 0.6553 & 0.6189 & 1.4332 & 6.4033 & GF1B_PMS & 20190814 \\
\hline Dunhuang new test site & 0.6176 & 0.8086 & 1.0056 & 1.6654 & GF1B_PMS & 20190814 \\
\hline Dazaohuo east & 0.4517 & 0.9761 & 1.0308 & 1.7289 & GF1_PMS2 & 20190814 \\
\hline Dazaohuo west & 0.6963 & 0.9843 & 0.9787 & 1.2650 & GF1_PMS1 & 20190814 \\
\hline
\end{tabular}




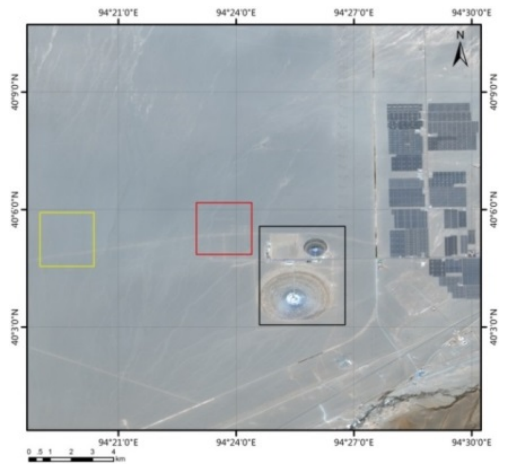

Figure 2. Location of the solar power station

The calculation results of the site space uniformity show that when the site area is less than $5 \mathrm{~km} \times 5 \mathrm{~km}$, the coefficient of variation of each site is less than $1.5 \%$; when the site area is $5 \mathrm{~km} \times 5 \mathrm{~km}$, the coefficient of variation of the Dunhuang national test site can reach $6.4 \%$. The high coefficient of variation is due to the solar power station near the Dunhuang national test site, as shown by the black box in Figure 2. In general, the coefficient of variation of the Dunhuang new test site, the Dazaohuo east and the Dazaohuo west are relatively smaller than that of the Dunhuang national test site, the spatial uniformity is superior to the Dunhuang national test site.

\subsection{Site radiometric stability}

In 2013-2019, four bands (bands 2-5) of Landsat8 were selected for each quarter, with the site latitude and longitude as the center point, the site size was $600 \mathrm{~m} \times 600 \mathrm{~m}$, corresponding to the $20 * 20$ pixels of the Landsat 8 satellite, and the site radiometric stability was
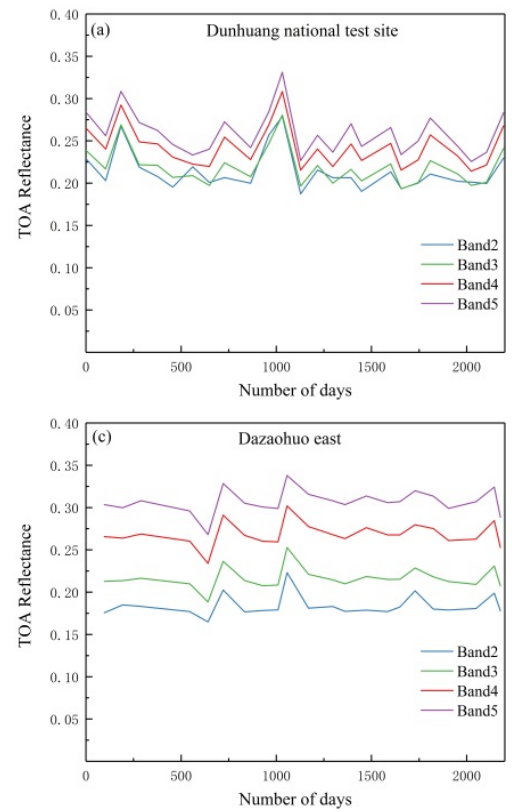

evaluated. First, determining the Landsat 8 image based on latitude and longitude, and calculating the average gray value of the corresponding site; Then, according to the radiometric calibration coefficients of each band, the corresponding apparent radiance is calculated; According to the solar zenith angle and the solar equivalent irradiance of each band, the apparent reflectance of each band is obtained by formula (1). The specific results are shown in Figure 3(a-d) and Table 2.

$$
\rho_{i}=\frac{L_{i} \times \pi}{E_{0, i} \mu_{s}}
$$

Where $\rho_{i}$ is the apparent reflectance of the $i$ th band, $L i$ is the apparent radiance of the $i$ th band, calculated from the calibration factor, which is $L_{i}=D N_{i} \times$ gain + offset,$D N_{i}$ is the average gray value of the $i$ th band, gain and offset are calibration factors, from the official website of the Resource Satellite Center. $E_{0, i}$ is the atmospheric equivalent irradiance of the $i$ th band, and $\mu_{s}$ is the cosine of the solar zenith angle.
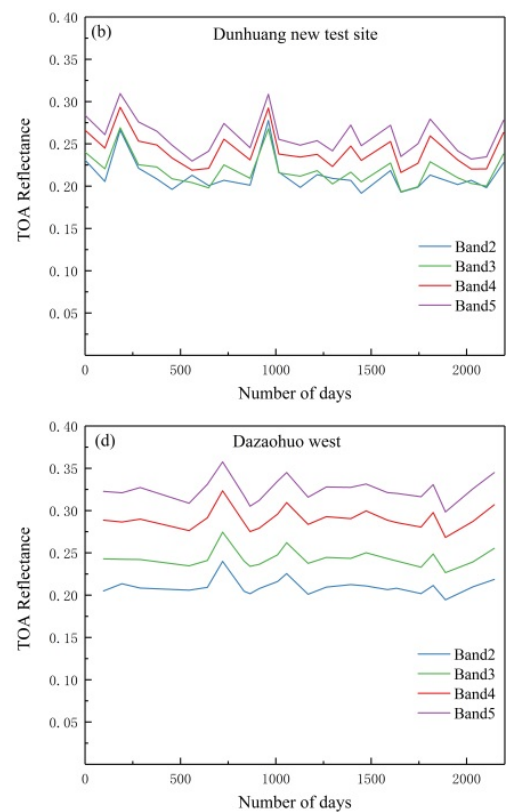

Figure 3. Apparent reflectance of each site

(a) Dunhuang national test site (b) Dunhuang new test site (c) Dazaohuo east (d) Dazaohuo west 
Table 2 Site radiometric stability

\begin{tabular}{|c|c|c|c|c|c|c|c|c|c|}
\hline \multirow{2}{*}{ site } & \multicolumn{4}{|c|}{ mean } & \multicolumn{4}{|c|}{ Coefficient of variation $\%$} & \multirow{2}{*}{ Number of images } \\
\hline & Band2 & Band3 & Band4 & Band5 & Band2 & Band3 & Band4 & Band5 & \\
\hline Dunhuang national test site & 0.2110 & 0.2157 & 0.2390 & 0.2560 & 10.9842 & 10.3318 & 10.1711 & 10.1509 & 25 \\
\hline Dunhuang new test site & 0.2129 & 0.2184 & 0.2424 & 0.2594 & 9.6051 & 8.8984 & 8.7164 & 8.4762 & 25 \\
\hline Dazaohuo east & 0.1838 & 0.2164 & 0.2686 & 0.3069 & 6.7381 & 5.7953 & 5.1476 & 4.6545 & 22 \\
\hline Dazaohuo west & 0.2101 & 0.2437 & 0.2901 & 0.3247 & 4.4317 & 4.2242 & 4.2301 & 4.1898 & 22 \\
\hline
\end{tabular}

In Figure 3, the abscissa is the number of days elapsed since May 14, 2013, and the ordinate is the apparent reflectance. It can be seen that the fluctuation of the Dunhuang national test site is the largest, followed by the Dunhuang new test site, and the fluctuations of the Dazaohuo east and the Dazaohuo west are the smallest, the apparent reflectance of each site in the four bands has the same trend. It can be seen from Table 3 that the variation coefficient of the Dazaohuo west is the smallest and the radiometric stability is the best, the Dazaohuo east is second best and the Dunhuang new test site is the third best. The radiometric stability of the above three sites is better than that of the Dunhuang national test site.

\subsection{Site spectral characteristics}

In August 2019, the SVC ground object spectrometer was used to perform spectral measurements at the Dunhuang national test site, the Dunhuang new test site, the Dazaohuo east, and the Dazaohuo west. The measured spectra of each site are shown in Figure 4. The surface of the Dazaohuo east and the Dazaohuo west are composed of fine sand, it is difficult for personnel, instruments and vehicles to enter the test sites. Therefore, spectral measurements were taken only at the edge of the test sites, and the spectral data of the edges were used to represent the spectral data of the entire site.

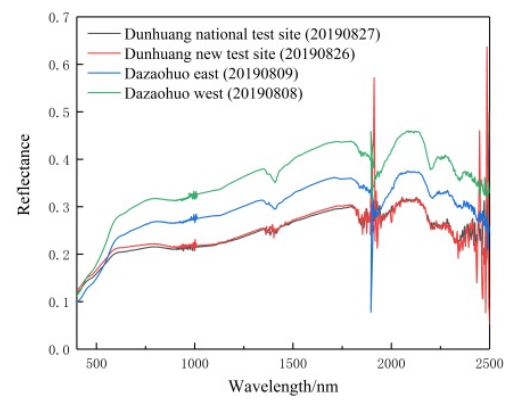

Figure 4. Measured spectral curves of each site

It can be seen that the measured spectra of the sites have the same trend. The surface reflectance of the Dunhuang national test site and the Dunhuang new test site is close. The surface reflectance of the Dazaohuo east and the Dazaohuo west are higher than that of the Dunhuang national test site, and the surface reflectance of the Dazaohuo west is the highest.
4.4. Site surface directional characteristics

The four bands of different angles of MODIS (bands 1-4) are used, with the site latitude and longitude as the center point, and the site size is $5 \mathrm{~km} \times 5 \mathrm{~km}$, corresponding to MODIS satellite $10 * 10$ pixels, and the relative difference of apparent reflectance is calculated. The specific results are shown in Table 3 - Table 6.

Table 3 Surface directional characteristics of the Dunhuang national test site

\begin{tabular}{|c|c|c|c|c|c|}
\hline & Image date & Satellite zenith $\left({ }^{\circ}\right)$ & Satellite azimuth $(\circ)$ & Solar zenith $(\circ)$ & Solar azimuth $(\circ)$ \\
\hline \multirow{3}{*}{$\begin{array}{c}\text { Geometric } \\
\text { information }\end{array}$} & 2019.08 .10 & 59.85 & 93.43 & 34.71 & 126.57 \\
\cline { 2 - 7 } & 2019.08 .10 & 62.76 & -70.56 & 24.70 & 171.03 \\
\cline { 2 - 7 } & 2019.08 .11 & 5.49 & 106.93 & 29.09 & 143.26 \\
\hline
\end{tabular}


The International Archives of the Photogrammetry, Remote Sensing and Spatial Information Sciences, Volume XLII-3/W10, 2020 International Conference on Geomatics in the Big Data Era (ICGBD), 15-17 November 2019, Guilin, Guangxi, China

\begin{tabular}{|c|c|c|c|c|c|}
\hline & & Band1 & Band2 & Band3 & Band4 \\
\hline \multirow{3}{*}{$\begin{array}{c}\text { Apparent } \\
\text { reflectance }\end{array}$} & 2019.08 .10 & 0.2075 & 0.1923 & 0.1987 & 0.2135 \\
\cline { 2 - 6 } & 2019.08 .10 & 0.1674 & 0.1642 & 0.1721 & 0.1867 \\
\cline { 2 - 7 } & 2019.08 .11 & 0.1754 & 0.1798 & 0.1919 & 0.2041 \\
\hline \multirow{2}{*}{\begin{tabular}{c} 
Difference \\
\cline { 2 - 7 }
\end{tabular}} & Forward scattering difference \% & 18.3010 & 6.9522 & 3.5435 & 4.6056 \\
\cline { 2 - 6 } & Back scattering difference \% & 4.5610 & 8.6763 & 10.3179 & 8.5252 \\
\hline
\end{tabular}

Table 4 Surface directional characteristics of the Dunhuang new test site

\begin{tabular}{|c|c|c|c|c|c|}
\hline & Image date & Satellite zenith $(\circ)$ & Satellite azimuth $\left({ }^{\circ}\right)$ & Solar zenith $\left({ }^{\circ}\right)$ & Solar azimuth $(\circ)$ \\
\hline \multirow{4}{*}{$\begin{array}{l}\text { Geometric } \\
\text { information }\end{array}$} & 2019.08 .10 & 59.96 & 93.93 & 34.73 & 126.51 \\
\hline & 2019.08 .10 & 62.64 & -70.40 & 24.69 & 170.89 \\
\hline & 2019.08 .11 & 5.92 & 104.65 & 29.11 & 143.14 \\
\hline & & Band1 & Band2 & Band3 & Band4 \\
\hline \multirow{3}{*}{$\begin{array}{l}\text { Apparent } \\
\text { reflectance }\end{array}$} & 2019.08.10 & 0.2069 & 0.1929 & 0.2004 & 0.2144 \\
\hline & 2019.08 .10 & 0.1701 & 0.1700 & 0.1784 & 0.1927 \\
\hline & 2019.08 .11 & 0.1742 & 0.1781 & 0.1889 & 0.1996 \\
\hline \multirow{2}{*}{ Difference } & Forward scattering difference $\%$ & 18.7715 & 8.3099 & 6.0879 & 7.4148 \\
\hline & Back scattering difference $\%$ & 2.3536 & 4.5480 & 5.5585 & 3.4569 \\
\hline
\end{tabular}

Table 5 Surface directional characteristics of the Dazaohuo east

\begin{tabular}{|c|c|c|c|c|c|}
\hline & Image date & Satellite zenith $(\circ)$ & Satellite azimuth $\left({ }^{\circ}\right)$ & Solar zenith $\left({ }^{\circ}\right)$ & Solar azimuth $\left({ }^{\circ}\right)$ \\
\hline \multirow{3}{*}{$\begin{array}{l}\text { Geometric } \\
\text { information }\end{array}$} & 2019.08.10 & 58.81 & 94.36 & 32.56 & 122.10 \\
\hline & 2019.08.11 & 1.70 & -88.79 & 26.17 & 138.93 \\
\hline & & Band1 & Band2 & Band3 & Band4 \\
\hline \multirow{2}{*}{$\begin{array}{l}\text { Apparent } \\
\text { reflectance }\end{array}$} & 2019.08 .10 & 0.1900 & 0.2037 & 0.2458 & 0.2905 \\
\hline & 2019.08.11 & 0.1596 & 0.1901 & 0.2384 & 0.2780 \\
\hline Difference & Forward scattering difference $\%$ & 19.0476 & 7.1541 & 3.1040 & 4.4964 \\
\hline
\end{tabular}

Table 6 Surface directional characteristics of the Dazaohuo west

\begin{tabular}{|c|c|c|c|c|c|}
\hline & Image date & Satellite zenith $\left({ }^{\circ}\right)$ & Satellite azimuth $\left({ }^{\circ}\right)$ & Solar zenith $(\circ)$ & Solar azimuth $\left({ }^{\circ}\right)$ \\
\hline \multirow{3}{*}{$\begin{array}{l}\text { Geometric } \\
\text { information }\end{array}$} & 2019.08 .10 & 60.04 & 93.88 & 32.93 & 121.81 \\
\hline & 2019.08.11 & 1.74 & 118.16 & 26.50 & 138.48 \\
\hline & & Band1 & Band2 & Band3 & Band4 \\
\hline \multirow{2}{*}{$\begin{array}{l}\text { Apparent } \\
\text { reflectance }\end{array}$} & 2019.08 .10 & 0.2069 & 0.2203 & 0.2555 & 0.2952 \\
\hline & 2019.08 .11 & 0.1745 & 0.2049 & 0.2446 & 0.2797 \\
\hline Difference & Forward scattering difference $\%$ & 18.5673 & 7.5159 & 4.4563 & 5.5417 \\
\hline
\end{tabular}

It can be seen from Table 4 that under the same site, the apparent reflectance calculated is different for MODIS images with different satellite azimuths. When forward scattering, the apparent reflectance obtained is quite different from that of vertical scattering, and the relative difference is up to $19 \%$; when back scattering, the apparent reflectance obtained is slightly different from that of vertical scattering, and the relative difference is less than 6\%; the apparent reflectance at the time of back scattering is close to vertical scattering, and the apparent reflectance at forward scattering is significantly higher than that of back scattering. This is because the surface is a rough surface composed of lighted soil and shadowed soil, the proportion of lighted soil in forward scattering is high, resulting in high reflectance; the proportion of shadowed soil in back scattering and vertical scattering is high, resulting in low reflectance.

It can be seen from Table 3 and Table 4 that the relative differences between back scattering and vertical scattering in each band in Table 3 are $4.56 \%, 8.68 \%$, 
$10.32 \%, 8.53 \%$, while the relative differences in Table 4 are $2.35 \%, 4.55 \%, 5.56 \%, 3.46 \%$. In the case of back scattering, the relative difference in the four bands of the Dunhuang national test site is twice that of the Dunhuang new test site. The relative differences between forward scattering and vertical scattering in each band in Table 3 are $18.30 \%, 6.95 \%, 3.54 \%, 4.61 \%$, while the relative differences in Table 4 are $18.77 \%, 8.31 \%, 6.09 \%$, 7.41\%. In the forward scattering, the Dunhuang national test site has significant differences with the Dunhuang new test site in the last three bands. The reason for the large difference between the two sites is that the Dunhuang national test site is close to the solar power station (as shown by the black box in Figure 2), resulting in an abnormal apparent reflectance.

From the forward scattering and vertical scattering in Table 3 to Table 6 , it can be seen that the relative
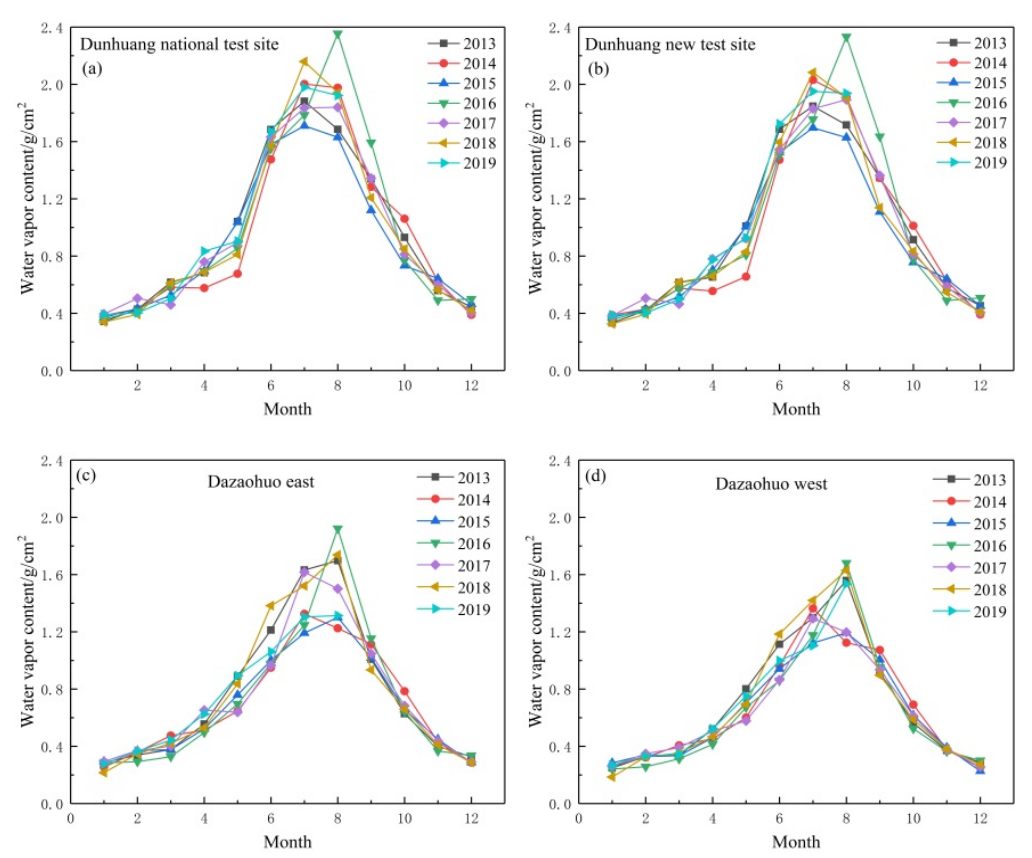

Figure 5. Monthly average water vapor content changes

(a) Dunhuang national test site (b) Dunhuang new test site (c) Dazaohuo east (d) Dazaohuo west

Table 7 Annual average water vapor content changes

\begin{tabular}{|c|c|c|c|c|c|c|c|c|}
\hline $\begin{array}{c}\text { Water vapor content } \\
\left(\mathrm{g} / \mathrm{cm}^{2}\right)\end{array}$ & $\begin{array}{c}\text { Year } \\
2013\end{array}$ & $\begin{array}{c}\text { Year } \\
2014\end{array}$ & $\begin{array}{c}\text { Year } \\
2015\end{array}$ & $\begin{array}{c}\text { Year } \\
2016\end{array}$ & $\begin{array}{c}\text { Year } \\
2017\end{array}$ & $\begin{array}{c}\text { Year } \\
2018\end{array}$ & $\begin{array}{c}\text { 6-year } \\
\text { average }\end{array}$ & Dynamic range \\
\hline Dunhuang national test site & 0.9698 & 0.9550 & 0.9121 & 0.9970 & 0.9567 & 0.9632 & 0.9590 & $0.9121 \sim 0.9970$ \\
\hline Dunhuang new test site & 0.9644 & 0.9495 & 0.9023 & 0.9877 & 0.9574 & 0.9451 & 0.9511 & $0.9023 \sim 0.9877$ \\
\hline Dazaohuo east & 0.7792 & 0.6969 & 0.6855 & 0.7287 & 0.7414 & 0.7735 & 0.7342 & $0.6855 \sim 0.7792$ \\
\hline Dazaohuo west & 0.6947 & 0.6574 & 0.6352 & 0.6465 & 0.6355 & 0.7001 & 0.6616 & $0.6352 \sim 0.7001$ \\
\hline
\end{tabular}

It can be seen from Figure 5 that in the different months, the monthly average water vapor content of each difference in apparent reflectance of the blue band, green band, red band and near infrared band are $18.30 \% \sim 19.05 \%, \quad 6.95 \% \sim 8.31 \% ， 3.10 \% \sim 6.09 \% ， 4.50 \%$ $\sim 7.41 \%$. The relative difference in apparent reflectance of the blue band is large, and BRDF correction is required; the apparent reflectance difference of the green band, the red band, and the near infrared band is less than $8.5 \%$. The relative differences in apparent reflectance of the four bands in each site have the same trend, the blue band is the largest, the red band is the smallest, and the Lambertian properties of each site are similar.

\subsection{Site water vapor content}

Using the time series of MODIS water vapor content products from 2013 to 2019, the variation of water vapor content was calculated to achieve quantitative evaluation of water vapor content at each site. The results are shown in Figure 5 (a-d) and Table 7.

site increased first and then decreased, with the highest content in July and August, the lowest content in January 
and December, wet in summer and dry in winter. The monthly average water vapor content of the Dunhuang national test site, the Dunhuang new test site, the Dazaohuo east and the Dazaohuo west are $2.35 \mathrm{gm} / \mathrm{cm}^{2}$, $2.33 \mathrm{gm} / \mathrm{cm}^{2}, 1.92 \mathrm{~g} / \mathrm{cm}^{2}, 1.68 \mathrm{~g} / \mathrm{cm}^{2}$, and the lowest are $0.34 \mathrm{~g} / \mathrm{cm}^{2}, 0.33 \mathrm{~g} / \mathrm{cm}^{2}, 0.22 \mathrm{~g} / \mathrm{cm}^{2}, 0.19 \mathrm{~g} / \mathrm{cm}^{2}$.

It can be seen from Table 7 that in different years, the annual average water vapor content of each site is basically the same, and the dynamic range is within 0.1 $\mathrm{g} / \mathrm{cm}^{2}$. The six-year average water vapor content of the Dunhuang national test site, the Dunhuang new test site, the Dazaohuo east and the Dazaohuo west are $0.96 \mathrm{~g} / \mathrm{cm}^{2}$, $0.95 \mathrm{~g} / \mathrm{cm}^{2}, 0.73 \mathrm{~g} / \mathrm{cm}^{2}, 0.66 \mathrm{~g} / \mathrm{cm}^{2}$. The average value of water vapor in the Dunhuang national test site and the Dunhuang new test site are significantly higher than that of the Dazaohuo east and the Dazaohuo west.
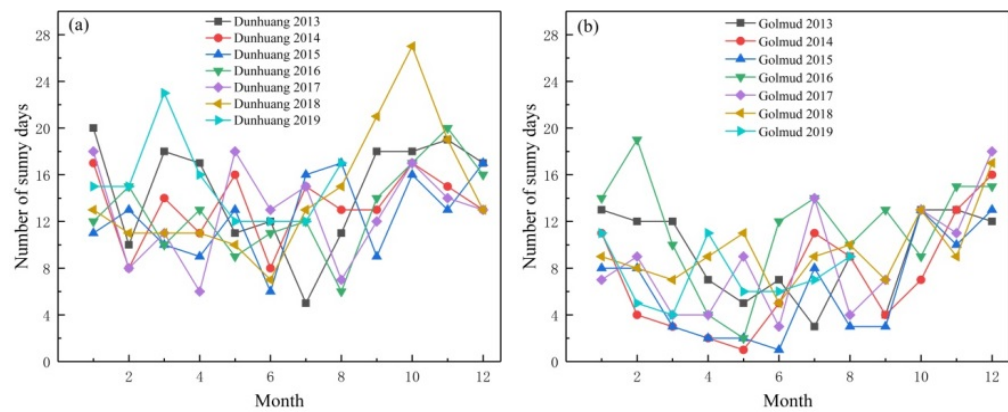

Figure 6. Number of sunny days in each month

(a) Dunhuang area (b) Golmud area

Table 8 Number of sunny days in the year

\begin{tabular}{|c|c|c|c|c|c|c|c|c|}
\hline Number of sunny days & $\begin{array}{c}\text { Year } \\
2013\end{array}$ & $\begin{array}{c}\text { Year } \\
2014\end{array}$ & $\begin{array}{c}\text { Year } \\
2015\end{array}$ & $\begin{array}{c}\text { Year } \\
2016\end{array}$ & $\begin{array}{c}\text { Year } \\
2017\end{array}$ & $\begin{array}{c}\text { Year } \\
2018\end{array}$ & $\begin{array}{c}\text { Average } \\
\text { value }\end{array}$ & $\begin{array}{c}\text { Dynamic } \\
\text { range }\end{array}$ \\
\hline Dunhuang & 176 & 160 & 150 & 155 & 152 & 171 & 161 & $150 \sim 176$ \\
\hline Golmud & 110 & 86 & 74 & 137 & 103 & 114 & 104 & $74 \sim 137$ \\
\hline
\end{tabular}

Table 9 Average number of sunny days per month in different years

\begin{tabular}{|c|c|c|c|c|c|c|c|c|c|c|c|c|}
\hline Number of sunny days & Jan. & Feb. & Mar. & Apr. & May. & June. & July. & Aug. & Sept. & Oct. & Nov. & Dec. \\
\hline Dunhuang & 15.2 & 10.8 & 12.3 & 11.2 & 12.8 & 9.5 & 12.7 & 11.5 & 14.5 & 18.7 & 16.7 & 14.8 \\
\hline Golmud & 10.3 & 10.0 & 6.5 & 4.7 & 5.0 & 5.5 & 9.8 & 7.5 & 6.3 & 11.3 & 11.8 & 15.2 \\
\hline
\end{tabular}

It can be seen from Figure 6 that in different months, the number of sunny days in the Dunhuang area is mostly between 6 and 20 days, the maximum is 27 days in October 2018, and the minimum is 5 days in July 2013. The number of sunny days in the Golmud area is between 2 and 16 days, the maximum is 19 days in February 2019, the minimum is 1 day in May 2014 and June 2015.

It can be seen from Table 8 that there is no obvious trend of the number of sunny days in Dunhuang and
Golmud areas. The average annual number of sunny days in Dunhuang is 161 days, and the dynamic range is 150 176 days. The average annual number of sunny days in Golmud is 104 days, and the dynamic range is $74 \sim 137$ days. The number of sunny days in Golmud varies greatly, and the number of sunny days in Dunhuang is relatively stable.

It can be seen from Table 9 that except for December, the number of sunny days in Dunhuang is significantly 
higher than that of Golmud. Radiometric calibration tests are concentrated from May to October each year, at this time, there are more sunny days in September and October in Dunhuang, and more sunny days in July and October in Golmud, which is suitable for the radiometric calibration tests.

\section{Conclusions}

In view of the urgent need for radiometric calibration site in China, this paper uses Landsat8 image to select the three most uniform areas in Dunhuang and Golmud as new radiometric calibration sites. Using high-resolution satellite panchromatic images, Landsat8 multi-spectral imagery, site measured spectra, MODIS images, MODIS water vapor products and historical weather, the four sites of the Dunhuang national test site, the Dunhuang new test site, the Dazaohuo east and the Dazaohuo west are analyzed. Including uniformity, stability, spectral properties, directional characteristics, water vapor content and number of sunny days.

(1) Spatial uniformity: When the site area is $5 \mathrm{~km} \times 5 \mathrm{~km}$, the coefficient of variation of the Dunhuang national test site, the Dunhuang new test site, the Dazaohuo east and the Dazaohuo west are $6.40 \%, 1.67 \%, 1.73 \%$, and $1.27 \%$. The spatial uniformity of the Dunhuang new test site, the Dazaohuo east and the Dazaohuo west are better than that of the Dunhuang national test site.

(2) Radiometric stability: The coefficient of variation in the blue band of the Dunhuang national test site, the Dunhuang new test site, the Dazaohuo east and the Dazaohuo west are $10.98 \%, 9.61 \%, 6.74 \%$, and $4.43 \%$. The radiometric stability of the Dazaohuo west is the best, the Dazaohuo east is the second, and the Dunhuang new test site is the third. The radiometric stability of the above three sites is better than that of the Dunhuang national test site.

(3) Spectral characteristics: The measured spectra of the sites have the same trend. The surface reflectance of the Dunhuang national test site and the Dunhuang new test site is close. The surface reflectance of the Dazaohuo east and the Dazaohuo west are higher than that of the Dunhuang national test site, and the surface reflectance of the Dazaohuo west is the highest.

(4) Surface directional characteristics: The apparent reflectance at the time of back scattering is close to vertical scattering, and the apparent reflectance at forward scattering is significantly higher than that of back scattering. For forward scattering, the relative differences in apparent reflectance of the four bands in each site have the same trend, the blue band is the largest, the red band is the smallest, and the Lambertian properties of each site are similar.

(5) Water vapor content: The six-year average water vapor content of the Dunhuang national test site, the Dunhuang new test site, the Dazaohuo east and the Dazaohuo west are $0.96 \mathrm{~g} / \mathrm{cm}^{2}, 0.95 \mathrm{~g} / \mathrm{cm}^{2}, 0.73 \mathrm{~g} / \mathrm{cm}^{2}$, $0.66 \mathrm{~g} / \mathrm{cm}^{2}$. The average value of water vapor in the Dunhuang national test site and the Dunhuang new test site are significantly higher than that of the Dazaohuo east and the Dazaohuo west, therefore, the Dazaohuo east and the Dazaohuo west are drier than the Dunhuang national test site and the Dunhuang new test site.

(6) Number of sunny days: The average annual number of sunny days in Dunhuang is 161 days, and the dynamic range is $150 \sim 176$ days. The average annual number of sunny days in Golmud is 104 days, and the dynamic range is 74 137 days. The number of sunny days in the Dunhuang area is significantly higher than that in the Golmud area, and the number of sunny days is more stable.

In summary, the newly selected three radiometric calibration sites are superior to the Dunhuang national test site in terms of spatial uniformity and radiometric stability; each site has similar spectral characteristics and surface directional characteristics, requiring BRDF correction. The Golmud area is drier than the Dunhuang area, and the number of sunny days in the Dunhuang area is higher than in the Golmud area. The newly selected three sites meet the requirements of the radiometric calibration site and are suitable for on-orbit radiometric calibration of satellite sensors, which provides a reference for the selection and evaluation of future calibration sites.

\section{Acknowledgement}

Fund project: National Key R\&D Program of China, 2018YFB0504900, 2018YFB0504903

\section{References}

[1]Gao,C.,Jiang,X.,Li,X.,Li,X.,2013:The cross-calibration of CBERS-02B/CCD visible-near infrared channels with 
Terra/MODIS channels. Int. J. Remote Sens, 34(9-10), 3688-3698. doi.org/10.1080/01431161.2012.716531.

[2]Liu,Q.,Yu,T.,Gao,H.,2019:Radiometric crosscalibration of GF-1 PMS sensor with a new BRDF model. Remote Sens,11(6), 707. doi.org/10.3390/rs11060707.

[3]Gao,H.,Gu,X.,Yu,T.,Gong,H.,2010:HJ-1A HSI on-orbit radiometric calibration and validation research. Sci China Tech Sci, 53,3119-3128. doi. org/10.1007/s11431-010- 41 13-2.

[4]Wang,M.,Zhou,S.,He,M.,Chen,X.,2015:Comparative analysis of characteristics of radiometric calibration sites of satellite remote sensors at home and abroad. Geomatics \& Spatial Information Technology,38(7),24-27.

[5]Gu,X.,Tian,G.,Yu,T.,Li,X.,Gao,H., 2013: Principle and method of radiometric calibration for aerospace optical remote sensor. Science Press.

[6]Gao,H.,Gu,X.,Yu,T.,Sun,Y.,Liu,Q.,2016:Cross-calibrat ion of GF-1 PMS sensor with Landsat 8 OLI and Terra MODIS. IEEE Trans. Geosci. Remote Sens, 54(8), 4847-4854. doi.org/ 10.1109/TGRS.2016.2552242.

[7]Chen,Y.,Sun,K.,Li,D.,Bai,T.,Huang,C.,2017:Radiometr ic cross-calibration of GF-4 PMS sensor based on assimilation of Landsat-8 OLI images. Remote Sens,9(8), 811.doi.org/10.3390/rs9080811. 